\title{
Specific Metabolic Characteristics of Women With Former Gestational Diabetes: the Importance of Adipose Tissue
}

\author{
D. VEJRAZKOVA ${ }^{1}$, M. VANKOVA ${ }^{1}$, P. LUKASOVA ${ }^{1}$, J. VCELAK $^{1}$, V. CIRMANOVA $^{1}$, \\ M. HALUZIK ${ }^{1}$, B. BENDLOVA ${ }^{1}$ \\ ${ }^{1}$ Institute of Endocrinology, Prague, Czech Republic
}

Received May 22, 2017

Accepted June 21, 2017

\begin{abstract}
Summary
Women with a positive history of gestational diabetes mellitus (GDM) face a higher risk of developing type 2 diabetes mellitus (T2DM) and metabolic syndrome later in life. The higher risk of these metabolic complications is closely associated with adipose tissue. In this review, the importance of adipose tissue is discussed in relation to GDM, focusing on both the quantity of fat deposits and the metabolic activity of adipose tissue in particular periods of life: neonatal age, childhood, adolescence, and pregnancy followed by nursing. Preventive measures based on body composition and lifestyle habits with special attention to the beneficial effects of breastfeeding are also discussed.
\end{abstract}

\section{Key words}

Gestational diabetes mellitus • Adipose tissue • Insulin sensitivity

- Adipokines • Breastfeeding

\section{Corresponding author}

D. Vejrazkova, Department of Molecular Endocrinology, Institute of Endocrinology, Narodni 8, 11694 Prague 1, Czech Republic. Fax: +420 224905 325. E-mail: dvejrazkova@endo.cz

\section{At birth}

Our health over the course of life can be to some extent predetermined at birth. In addition to factors like the geographical position of the country where we are born, the socioeconomic status and education of the family with their influence on lifestyle habits, and genetic factors, another such predictor can be body weight at birth. Both low and high birth weight have been well documented to be risk factors for type 2 diabetes mellitus
(T2DM) and features of metabolic syndrome including insulin resistance, hypertension, and dyslipidemia.

Hales et al. (1991) demonstrated an inverse relationship between birth weight and risk for T2DM later in life. Subsequently, many studies have contributed to the growing body of evidence that supports an association of low birth weight with high blood pressure and abnormal lipid profiles (Barker et al. 1993a, RichEdwards et al. 1999). These findings demonstrate a negative correlation between the percentiles of birth weight and the risk of various metabolic abnormalities in adulthood, and have led to low birth weight being used as a proxy for suboptimal fetal organogenesis (Ogonowski et al. 2014), in line with Barker's hypothesis of fetal programming (Barker et al. 1993b). Concurrently, high birth weight has also been found to be linked with an increased risk of insulin resistance and T2DM (McCance et al. 1994, Wei et al. 2003).

Studies in the past two decades have also presented associations of low and high birth weight with gestational diabetes mellitus (GDM). GDM is a prevalent complication of pregnancy that strongly predicts the later development of T2DM and shares many features of metabolic syndrome (Williams et al. 1999, Innes et al. 2002, Seghieri et al. 2002, Savona-Ventura and Chircop 2003, Claesson et al. 2007, Yeung et al. 2010). Williams et al. (1999) demonstrated that low birth weight women are at increased risk for GDM in white populations, but that in African-American populations, rather high birth weight women experienced an increased risk of GDM. This U-shape distribution, with a greater proportion of GDM women having low as well as high birth weight, 
has since been also described by many others (Innes et al. 2002, Savona-Ventura and Chircop 2003, Claesson et al. 2007). In a lagre cohort of more than 116,500 Danish mothers, being born premature or with low birth weight for gestational age was associated with an increased risk of GDM and pre-eclampsia, while high birth weight for gestational age was associated with an increased risk of GDM, but with a decreased risk of pre-eclampsia. Importantly, inappropriate weight for gestational age was a more significant risk factor than prematurity per se (á Rogvi et al. 2012). However, differences have been found between studies on the newborn low/high birth weight limits and the degree of associated risk. For example, in one study, birth weight $<2,600 \mathrm{~g}$ was associated with a twofold higher risk of the development of GDM in adulthood (odds ratio $=1.89 \quad[95 \% \mathrm{CI}$ 1.088-3.285], $\mathrm{p}=0.02$ ), and this association was independent of major confounders such as age, parity, family history of T2DM, and pre-pregnancy body weight (Seghieri et al. 2002).

Research studying this issue in the Czech population was published in 2010 and 2015 by our team at the Institute of Endocrinology (Vejražková et al. 2010, Vejrazkova et al. 2015). A long-term study was undertaken to analyze birth weight in relation to GDM status and to other components of metabolic syndrome in adulthood using more than 600 participants (350 of them with positive history of GDM). The longitudinal design of the study allowed an evaluation of metabolic changes over years, and found that in women with former GDM, birth weight was systematically associated with glucose metabolism. In those born with low birth weight $(\leq 2,900 \mathrm{~g})$, there was lower peripheral insulin sensitivity persisting more than 5 years after delivery compared to those born with normal or high birth weight (Vejrazkova et al. 2015). Furthermore, our analysis of both genders found that high birth weight $(>3,750 \mathrm{~g})$ was associated with significantly higher BMI in adulthood, suggesting that large newborns are more likely to retain larger amounts of fat, including visceral fat, which predisposes them to impairments of insulin sensitivity later in life (Vejražková et al. 2010).

\section{Childhood}

Obesity in children is a significant predictor of obesity in adulthood, and is also a risk factor for numerous complications, including metabolic syndrome, T2DM, and GDM. According to the recent literature,
$20 \%$ of obese newborns will become obese children, $40 \%$ of obese children will become obese teenagers, and $80 \%$ of obese teenagers will become obese adults (Trandafir et al. 2016).

There is also a great deal of literature devoted to the relationship between maternal GDM and the risk of obesity in children born of these pregnancies. Recently, a large study on 6,909 children born to mothers with GDM concluded that these children were significantly more overweight at an early age (5-12 years) than those born to non-GDM mothers (Hakanen et al. 2016). Another large multinational cross-sectional study was carried out on 4,740 children aged 9-11 years (Zhao et al. 2016), with maternal GDM shown to be associated with an increased risk of childhood obesity; however, this association was not fully independent of maternal BMI. The odds ratios (multivariably adjusted for factors like maternal age at delivery, gestational age, education, infant feeding mode, sedentary time, sex, birth weight and some others) for children of GDM mothers in comparison with children of non-GDM mothers were 1.53 [95 \% CI 1.03-2.27, $\mathrm{p}=0.034$ ] for obesity defined as BMI z-scores $>+2 \mathrm{SD}$, and 1.73 [95\% CI 1.14-2.62, $\mathrm{p}=0.010]$ for central obesity defined as waist circumference $\geq 90^{\text {th }}$ percentile of the NHANES III reference (Zhao et al. 2016). After an additional adjustment for current maternal BMI, the positive association was still significant for central obesity, but not for obesity defined by BMI. Therefore, along with maternal GDM, the question of maternal BMI and body fat distribution seems to be very important in predicting the obesity risk in children.

Considering the relationship between maternal GDM and the risk of obesity in children, the opposite issue arises: an association between obesity in childhood and subsequent GDM development in adulthood. That is, to what extent can obesity in girls be predictive for the development of GDM in their pregnancies? In the literature, increased maternal BMI has been stressed as a contributor to the increased incidence of GDM cases. Pre-pregnancy obesity was identified as the most potent predictor of GDM (Solomon et al. 1997, Zhang et al. 2006, Pirjani et al. 2016), with a recent prospective cohort study calculating the odds ratio as 2.74 [95\% CI 1.28-5.88, $\mathrm{p}=0.009$ ] (Pirjani et al. 2016). However, prospective studies monitoring obese girls until their pregnancy are absent. Our group evaluated data on the development of obesity in different periods of life including pre-school age, school age and adolescence in a cohort of 580 former 
GDM patients and non-GDM women with normal fasting glucose. Out of all the obese women (BMI $\left.>30 \mathrm{~kg} / \mathrm{m}^{2}\right)$ in this cohort, $53 \%$ in the GDM group reported obesity already in childhood, compared to only $15 \%$ in the control non-GDM group ( $\mathrm{Chi}^{2}=10, \mathrm{p}=0.001$; unpublished data). This highly suggests that childhood is a crucial period of life in terms of the ability of excess fat to predispose individuals to metabolic complications later in life. Therefore, it is extremely important to emphasize the importance of obesity prevention in children.

\section{Toward adulthood and pregnancy}

\section{The metabolic role of adipose tissue during life}

Adipocytes consist of functionally distinct cellular subtypes, with white adipocytes serving as energy storage deposits (apart from many other active functions discussed below) and brown adipocytes serving primarily as energy dissipators producing heat. White and brown adipocytes are also morphologically distinct and their developmental origins are different. Recent studies have revealed a vascular or perivascular localization of white adipocyte progenitors, whereas brown fat shares a developmental origin with the skeletal muscle expressing specific myogenic marker genes (Yang et al. 2014). Brown adipose tissue is especially abundant in newborns. Due to their low amount of musculature and inability to shiver, brown fat is of great importance to avoid hypothermia. It is also present and metabolically active in adult humans, but its proportion decreases with age. Of note, heat is generated also outside classical brown adipose tissue deposits in adipocytes termed 'brite' (brown-in-white) or 'beige'. The presence of 'brite/beige' adipocytes correlates with a lean, metabolically healthy phenotype, but causality is not yet clear. White adipose tissue composes as much as 20-30\% of the body weight in non-obese adult women. The initiation and maturation of adipose tissue is a complex process, and an interplay between insulin and growth hormone is essential in its regulation (Zhang et al. 2016). After termination of the growth phase in adolescence or early adulthood, adipose tissue continues to play its important role in whole-body energy homeostasis by regulating glucose and lipid metabolism.

Adipose tissue is well known for its endocrine function and for its role in inflammation and the immune response. There is robust evidence suggesting that obesity and low-grade inflammation are major players in the development of insulin resistance. Adipokines such as adiponectin, leptin, resistin and visfatin are secreted by white adipose tissue, and to a large extent determine the degree of adipose tissue inflammation and thus the predisposition for the development of insulin resistance. It is also noteworthy that lean subjects can develop inflammation-associated insulin resistance (Mehta et al. 2010). Under certain circumstances, lean insulin-resistant subjects may have a higher proinflammatory adipokine profile than overweight but insulin-sensitive subjects (Moscavitch et al. 2016). However, in most individuals, insulin resistance and obesity coexist and are associated with an increased risk of inflammation and subsequent diabetes.

During pregnancy, adipokines are produced not only by the adipose tissue but also by the placenta. There is evidence to suggest that the placenta substantially contributes to maternal adipokine concentrations (Sartori et al. 2016). A dysregulation of placental function related to insulin sensitivity and inflammation was reported in pregnancies with GDM (Valsamakis et al. 2010).

\section{Significant adipokines (adipose tissue derived peptide hormones) in relation to GDM}

Women diagnosed with GDM show signs of subclinical inflammation with decreased concentrations of adiponectin, the endogenous insulin-sensitizing hormone (Heitritter et al. 2005). Although adiponectin is expressed in adipose tissue, it paradoxically correlates negatively with obesity. Nevertheless, some studies have found lower adiponectinemia as an adiposity-independent marker of decreased insulin sensitivity in women with former GDM (Vejrazkova et al. 2017a). There is strong and consistent evidence showing persistently low adiponectin levels during GDM pregnancies and during follow-up after birth (Bhograj et al. 2016, Lekva et al. 2017) in comparison with non-GDM women. Furthermore, according to recent observations, low adiponectin in GDM women may represent a risk factor for the future development of metabolic and cardiovascular disease (Lekva et al. 2017), as adiponectin may protect against the development of atherosclerosis by inhibiting endothelial inflammation and foam cell formation.

Quite an opposite metabolic effect on insulin sensitivity, subclinical inflammation and cardiovascular risk is observed with the adipokine leptin. While adiponectin down-regulates inflammatory mediators like $\mathrm{TNF} \alpha$ and interleukin-6, leptin up-regulates them. Leptin is positively associated with body adiposity and insulin resistance (Nasrat et al. 2016, Osegbe et al. 2016). Its levels increase throughout pregnancy, and a significant 
correlation between leptin and the degree of pregnancyinduced insulin resistance was described (Skvarca et al. 2013). In GDM women, higher leptinemia was found during pregnancy as well as 8 weeks postpartum compared to non-GDM women (Kautzky-Willer et al. 2001). Our group found higher leptinemia in lean former GDM women from one-half to one year after delivery, and this was associated with a higher oGTT-derived postchallenge glycemia, insulinemia, and index of insulin resistence (HOMA-IR) and a lower Cederholm index of insulin sensitivity compared to BMI-matched non-GDM women (Vejrazkova et al. 2017a).

Resistin was originally described as a factor contributing to the development of insulin resistance and diabetes in mice and humans; however, there is ongoing debate regarding its exact role in glucose and lipid metabolism. Many authors have reported that circulating resistin levels are increased in obesity (e.g. Sartori et al. 2016). Due to its role in the inflammatory response, including in several transcriptional and signaling pathways (resistin stimulates secretion of proinflammatory cytokines such as TNF $\alpha$ and interleukin-6), resistin may mediate the link between energy balance signaling and inflammatory processes. In pregnancy, resistin is highly expressed in the placenta, and plasma resistin levels in pregnant women are higher than in non-pregnant women. It has been hypothesized that placental resistin may have a physiological role in the regulation of maternal glucose by decreasing insulin sensitivity during pregnancy. Accordingly, maternal resistin concentrations have been reported to be higher in GDM women than in non-GDM controls (Noureldeen et al. 2014, Kuzmicki et al. 2009), although not all studies have confirmed this observation (Lappas et al. 2005). Of note, high concentrations of resistin in cord blood suggest that this hormone could be related to the control of fetal energy expenditure and adiposity (Sartori et al. 2016).

Visfatin is an endocrine, autocrine, and paracrine peptide with many functions including glycoregulation and immunomodulation. It was identified as a substance produced by lymphocytes acting on inflammatory regulation, and concurrently as a protein involved in $\beta$ cell maturation (Samal et al. 1994). In humans, visfatin is predominantly expressed in visceral adipose tissue and its expression correlates positively with visceral adiposity. In contrast, subcutaneous adipose tissue expresses low levels of visfatin (Araki et al. 2008). This may indicate an important link with altered glucose metabolism in visceral obesity, which is known to be accompanied by insulin resistance in adulthood. Visfatin exerts insulin-sensitizing and insulin-mimetic effects, so it has attracted attention for its possible application in glycemic control (Ahmed et al. 2015). Maternal visfatin concentrations in GDM women have been found to be higher compared to non-GDM controls in many studies (Noureldeen et al. 2014, Lewandowski et al. 2007, Ferreira et al. 2011), although contrasting results have also been reported (Telejko et al. 2009). Ferreira et al. (2011) found increased plasma visfatin levels in pregnant women who subsequently developed GDM, suggesting that visfatin could be a potential biomarker for the prediction of GDM. We also found that visfatin levels were higher in lean former GDM women one-half to one year after delivery, who also showed significantly higher oGTT-derived postchallenge glycemia, insulinemia, and HOMA-IR and a lower Cederholm index of insulin sensitivity compared to BMI-matched control non-GDM women (Vejrazkova et al. 2017a).

Pre-pregnancy body weight and weight gain in pregnancy

High pre-pregnancy body weight and excessive gestational weight gain are both associated with an increased risk of the development of GDM (Vidanalage et al. 2016, Boriboonhirunsarn 2016). Moreover, both independently contribute to adverse pregnancy outcomes (Zilberlicht et al. 2016). In GDM mothers, these conditions were associated with a higher incidence of LGA (large for gestational age) newborns (Miao et al. 2017). Furthermore, in a population-based cohort study with more than 3,000 women participating, it was shown that early adult weight gain prior to pregnancy even within the normal BMI range is also an important risk factor for the development of GDM, with a relative risk ranging from 2 to 2.9 compared with women with stable weight during adulthood (Adane et al. 2017). Thus, weight gain prevention starting in early adulthood appears to be the best strategy for preventing gestational diabetes in pregnancy. Additionally, maternal obesity and excessive gestational weight gain are independent risk factors of the child's overweight at an early age (BiderCanfield et al. 2017, Hillier et al. 2016).

\section{Breastfeeding - the best prevention for both mother and child}

Breastfeeding has been shown to decrease risk of the child becoming overweight. In a large cohort of more 
than 15,700 mother-offspring pairs, it was demonstrated that breastfeeding for at least 6 months had a significant protective effect against overweightness and obesity in the child that persisted up to 2 years of age (BiderCanfield et al. 2017). In addition to protecting against excessive fat accumulation, breastfeeding also confers protection against childhood infections and, later in life, against cardiovascular disease and T2DM (Victora et al. 2016, Aguilar Cordero et al. 2015, Martens et al. 2016).

Breastfeeding is beneficial not only for the child but also for the mother, especially for mothers previously diagnosed with GDM. Some studies have suggested that lactation is associated with lower blood glucose and insulin concentrations and improved glucose tolerance (Kjos et al. 1993, Tigas et al. 2002). One of our studies found higher insulin sensitivity (a higher Matsuda index of insulin sensitivity and lower HOMA-IR index of insulin resistance) in lactating women with a positive history of GDM compared to non-lactating GDM women. In this study, better insulin sensitivity in lactating GDM women was associated with lower leptin, resistin and visfatin levels, in line with the current knowledge concerning the metabolic activity of these adipokines (Vejražková et al. 2017b). Similarly, breastfeeding is associated with a reduced risk of diabetes among mothers, independently of GDM status or age of the mother (Martens et al. 2016). Lactation also has favorable effects on the lipid profile, with lactating women with recent GDM exhibiting higher HDL cholesterol and lower triglycerides compared to non-lactating women (Kjos et al. 1993, Gunderson et al. 2014, Vejražková et al. 2017b). As a consequence, mothers who breastfeed are less likely to suffer from cardiovascular disorders, including hypertension, both in the short term and, importantly, also in the long term, independently of GDM history (Aguilar Cordero et al. 2015). Last but not least, breastfeeding also gives protection against osteoporosis (Jiménez-Arreola and Aguilera Barreiro 2015) and against some specific types of cancer such as breast and ovarian cancer (Victora et al. 2016).

\section{Conclusion}

In conclusion, our adipose tissue presents a variety of pitfalls throughout our lives, and some periods, especially the prenatal period, childhood and pregnancy, are very important with regard to future health. For instance, in women with former GDM, adipose tissue can dramatically affect the manifestation of T2DM or features of metabolic syndrome. Some of the factors determining how we pass through these periods can be very significantly influenced by our decisions (life-style habits like nutrition and physical activity), some of them are more resistant but still modifiable (body composition), and some can be influenced only to a limited extent (fat tissue distribution) or cannot be influenced at all (birth weight). An important factor with long-term positive impacts on future health that can be easily adopted by the vast majority of mothers, is breastfeeding and its duration. It is thus necessary to provide information to promote breastfeeding and increase awareness about its positive impacts not only on the health of the child, but also on the health of mothers. These benefits of breastfeeding are especially important for GDM mothers, and this natural and accessible intervention may be effective in reducing the risk of developing many metabolic complications including T2DM.

\section{Conflict of Interest}

There is no conflict of interest.

\section{Acknowledgements}

This work was supported by the project NV17-30528A, $\mathrm{MH} \mathrm{CZ} \mathrm{-} \mathrm{DRO} \mathrm{(Institute} \mathrm{of} \mathrm{Endocrinology} \mathrm{-} \mathrm{EÚ,}$ 00023761) and by the MEYS CR (OP RDE, Excellent research - ENDO.CZ).

\section{Abbreviations}

BMI - body mass index, CI - confidence interval, GDM - gestational diabetes mellitus, HOMA-IR - insulin resistence index (homeostatic model assessment), oGTT - oral glucose tolerance test, NHANES - National Health and Nutrition Examination Survey, T2DM - type 2 diabetes mellitus, TNF $\alpha$ - tumor necrosis factor $\alpha$.

\section{References}

Á ROGVI R, FORMAN JL, DAMM P, GREISEN G: Women born preterm or with inappropriate weight for gestational age are at risk of subsequent gestational diabetes and pre-eclampsia. PLoS One 7: e34001, 2012.

ADANE AA, TOOTH LR, MISHRA GD: Pre-pregnancy weight change and incidence of gestational diabetes mellitus: a finding from a prospective cohort study. Diabetes Res Clin Pract 124: 72-80, 2017. 
AHMED MB, ISMAIL MI, MEKI AR: Relation of osteoprotegerin, visfatin and ghrelin to metabolic syndrome in type 2 diabetic patients. Int $J$ Health Sci 9: 127-139, 2015.

AGUILAR CORDERO MJ, MADRID BAÑOS N, BAENA GARCÍA L, MUR VILLAR N, GUISADO BARRILAO R, SÁNCHEZ LÓPEZ AM: Breastfeeding as a method to prevent cardiovascular diseases in the mother and the child. Nutr Hosp 31: 1936-1946, 2015.

ARAKI S, DOBASHI K, KUBO K, KAWAGOE R, YAMAMOTO Y, KAWADA Y, ASAYAMA K, SHIRAHATA A: Plasma visfatin concentration as a surrogate marker for visceral fat accumulation in obese children. Obesity (Silver Spring) 16: 384-388, 2008.

BARKER DJ, MARTYN CN, OSMOND C, HALES CN, FALL CH: Growth in utero and serum cholesterol concentrations in adult life. BMJ 307: 1524-1527, 1993a.

BARKER DJ, HALES CN, FALL CH, OSMOND C, PHIPPS K, CLARK PM: Type 2 (non-insulin-dependent) diabetes mellitus, hypertension and hyperlipidaemia (syndrome $\mathrm{X}$ ): relation to reduced fetal growth. Diabetologia 36: 62-67, 1993 b.

BHOGRAJ A, SURYANARAYANA KM, NAYAK A, MURTHY NS, DHARMALINGAM M, KALRA P: Serum adiponectin levels in gestational diabetes mellitus. Indian J Endocrinol Metab 20: 752-755, 2016.

BIDER-CANFIELD Z, MARTINEZ MP, WANG X, YU W, BAUTISTA MP, BROOKEY J, PAGE KA, BUCHANAN TA, XIANG AH: Maternal obesity, gestational diabetes, breastfeeding and childhood overweight at age 2 years. Pediatr Obes 12: 171-178, 2017.

BORIBOONHIRUNSARN D: Second trimester weight gain $>7 \mathrm{~kg}$ increases the risk of gestational diabetes after normal first trimester screening. J Obstet Gynaecol Res 43: 462-467, 2017.

CLAESSON R, ABERG A, MARSÁL K: Abnormal fetal growth is associated with gestational diabetes mellitus later in life: population-based register study. Acta Obstet Gynecol Scand 86: 652-656, 2007.

FERREIRA AF, REZENDE JC, VAIKOUSI E, AKOLEKAR R, NICOLAIDES KH: Maternal serum visfatin at 11-13 weeks of gestation in gestational diabetes mellitus. Clin Chem 57: 609-613, 2011.

GUNDERSON EP, KIM C, QUESENBERRY CP JR, MARCOVINA S, WALTON D, AZEVEDO RA, FOX G, ELMASIAN C, YOUNG S, SALVADOR N, LUM M, CRITES Y, LO JC, NING X, DEWEY KG: Lactation intensity and fasting plasma lipids, lipoproteins, non-esterified free fatty acids, leptin and adiponectin in postpartum women with recent gestational diabetes mellitus: the SWIFT cohort. Metabolism 63: 941-950, 2014.

HAKANEN T, SAHA MT, SALO MK, NUMMI T, HARJUNMAA U, LIPIÄINEN L, VUORELA N: Mothers with gestational diabetes are more likely to give birth to children who experience early weight problems. Acta Paediatr 105: 1166-1172, 2016.

HALES CN, BARKER DJ, CLARK PM, COX LJ, FALL C, OSMOND C, WINTER PD: Fetal and infant growth and impaired glucose tolerance at age 64. BMJ 303: 1019-1022, 1991.

HEITRITTER SM, SOLOMON CG, MITCHELL GF, SKALI-OUNIS N, SEELY EW: Subclinical inflammation and vascular dysfunction in women with previous gestational diabetes mellitus. J Clin Endocrinol Metab 90: 3983-3988, 2005.

HILLIER TA, PEDULA KL, VESCO KK, OSHIRO CE, OGASAWARA KK: Impact of maternal glucose and gestational weight gain on child obesity over the first decade of life in normal birth weight infants. Matern Child Health J 20: 1559-1568, 2016.

INNES KE, BYERS TE, MARSHALL JA, BARÓN A, ORLEANS M, HAMMAN RF: Association of a woman's own birth weight with subsequent risk for gestational diabetes. JAMA 287: 2534-2541, 2002.

JIMÉNEZ-ARREOLA J, AGUILERA BARREIRO MDE L: Breast feeding as preventive factor for osteoporosis in adult women (in Spanish). Nutr Hosp 32: 2600-2605, 2015.

KAUTZKY-WILLER A, PACINI G, TURA A, BIEGLMAYER C, SCHNEIDER B, LUDVIK B, PRAGER R, WALDHÄUSL W: Increased plasma leptin in gestational diabetes. Diabetologia 44: 164-172, 2001.

KJOS SL, HENRY O, LEE RM, BUCHANAN TA, MISHELL DR JR: The effect of lactation on glucose and lipid metabolism in women with recent gestational diabetes. Obstet Gynecol 82: 451-455, 1993.

KUZMICKI M, TELEJKO B, SZAMATOWICZ J, ZONENBERG A, NIKOLAJUK A, KRETOWSKI A, GORSKA M: High resistin and interleukin-6 levels are associated with gestational diabetes mellitus. Gynecol Endocrinol 25: 258-263, 2009. 
LAPPAS M, YEE K, PERMEZEL M, RICE GE: Release and regulation of leptin, resistin and adiponectin from human placenta, fetal membranes, and maternal adipose tissue and skeletal muscle from normal and gestational diabetes mellitus-complicated pregnancies. J Endocrinol 186: 457-465, 2005.

LEKVA T, MICHELSEN AE, AUKRUST P, HENRIKSEN T, BOLLERSLEV J, UELAND T: Leptin and adiponectin as predictors of cardiovascular risk after gestational diabetes mellitus. Cardiovasc Diabetol 16: 5, 2017.

LEWANDOWSKI KC, STOJANOVIC N, PRESS M, TUCK SM, SZOSLAND K, BIENKIEWICZ M, VATISH M, LEWINSKI A, PRELEVIC GM, RANDEVA HS: Elevated serum levels of visfatin in gestational diabetes: a comparative study across various degrees of glucose tolerance. Diabetologia 50: 1033-1037, 2007.

MARTENS PJ, SHAFER LA, DEAN HJ, SELLERS EA, YAMAMOTO J, LUDWIG S, HEAMAN M, PHILLIPSBECK W, PRIOR HJ, MORRIS M, MCGAVOCK J, DART AB, SHEN GX: Breastfeeding initiation associated with reduced incidence of diabetes in mothers and offspring. Obstet Gynecol 128: 1095-1104, 2016.

MCCANCE DR, PETTITT DJ, HANSON RL, JACOBSSON LT, KNOWLER WC, BENNETT PH: Birth weight and non-insulin dependent diabetes: thrifty genotype, thrifty phenotype, or surviving small baby genotype? $B M J$ 308: 942-945, 1994.

MEHTA NN, MCGILLICUDDY FC, ANDERSON PD, HINKLE CC, SHAH R, PRUSCINO L, TABITAMARTINEZ J, SELLERS KF, RICKELS MR, REILLY MP: Experimental endotoxemia induces adipose inflammation and insulin resistance in humans. Diabetes 59: 172-181, 2010.

MIAO M, DAI M, ZHANG Y, SUN F, GUO X, SUN G: Influence of maternal overweight, obesity and gestational weight gain on the perinatal outcomes in women with gestational diabetes mellitus. Sci Rep 7: 305, 2017.

MOSCAVITCH SD, KANG HC, FILHO RA, MESQUITA ET, NETO HC, ROSA ML: Comparison of adipokines in a cross-sectional study with healthy overweight, insulin-sensitive and healthy lean, insulin-resistant subjects, assisted by a family doctor primary care program. Diabetol Metab Syndr 8: 9, 2016.

NASRAT H, PATRA SK, GOSWAMI B, JAIN A, RAGHUNANDAN C: Study of Association of leptin and insulin resistance markers in patients of PCOS. Indian J Clin Biochem 31: 104-107, 2016.

NOURELDEEN AF, QUSTI SY, AL-SEENI MN, BAGAIS MH: Maternal leptin, adiponectin, resistin, visfatin and tumor necrosis factor-alpha in normal and gestational diabetes. Indian J Clin Biochem 29: 462-470, 2014.

OGONOWSKI J, MIAZGOWSKI T, ENGEL K, CELEWICZ Z: Birth weight predicts the risk of gestational diabetes mellitus and pregravid obesity. Nutrition 30: 39-43, 2014.

OSEGBE I, OKPARA H, AZINGE E: Relationship between serum leptin and insulin resistance among obese Nigerian women. Ann Afr Med 15: 14-19, 2016.

PIRJANI R, SHIRZAD N, QORBANI M, PHELPHELI M, NASLI-ESFAHANI E, BANDARIAN F, HEMMATABADI M: Gestational diabetes mellitus its association with obesity: a prospective cohort study. Eat Weight Disord, 2016. DOI: 10.1007/s40519-016-0332-2

RICH-EDWARDS JW, COLDITZ GA, STAMPFER MJ, WILLETT WC, GILLMAN MW, HENNEKENS CH, SPEIZER FE, MANSON JE: Birthweight and the risk for type 2 diabetes mellitus in adult women. Ann Intern Med 130: 278-284, 1999.

SAMAL B, SUN Y, STEARNS G, XIE C, SUGGS S, MCNIECE I: Cloning and characterization of the cDNA encoding a novel human pre-B-cell colony-enhancing factor. Mol Cell Biol 14: 1431-1437, 1994.

SARTORI C, LAZZERONI P, MERLI S, PATIANNA VD, VIAROLI F, CIRILLO F, AMARRI S, STREET ME: From placenta to polycystic ovarian syndrome: the role of adipokines. Mediators Inflamm 2016: 4981916, 2016.

SAVONA-VENTURA C, CHIRCOP M: Birth weight influence on the subsequent development of gestational diabetes mellitus. Acta Diabetol 40: 101-104, 2003.

SEGHIERI G, ANICHINI R, DE BELLIS A, ALVIGGI L, FRANCONI F, BRESCHI MC: Relationship between gestational diabetes mellitus and low maternal birth weight. Diabetes Care 25: 1761-1765, 2002.

SKVARCA A, TOMAZIC M, BLAGUS R, KRHIN B, JANEZ A: Adiponectin/leptin ratio and insulin resistance in pregnancy. J Int Med Res 41: 123-128, 2013.

SOLOMON CG, WILLETT WC, CAREY VJ, RICH-EDWARDS J, HUNTER DJ, COLDITZ GA, STAMPFER MJ, SPEIZER FE, SPIEGELMAN D, MANSON JE: A prospective study of pregravid determinants of gestational diabetes mellitus. JAMA 278: 1078-1083, 1997. 
TELEJKO B, KUZMICKI M, ZONENBERG A, SZAMATOWICZ J, WAWRUSIEWICZ-KURYLONEK N, NIKOLAJUK A, KRETOWSKI A, GORSKA M: Visfatin in gestational diabetes: serum level and mRNA expression in fat and placental tissue. Diabetes Res Clin Pract 84: 68-75, 2009.

TIGAS S, SUNEHAG A, HAYMOND MW: Metabolic adaptation to feeding and fasting during lactation in humans. J Clin Endocrinol Metab 87: 302-307, 2002.

TRANDAFIR LM, TEMNEANU OR: Pre- and post-natal risk and determination of factors for child obesity. $J$ Med Life 9: 386-391, 2016.

VALSAMAKIS G, KUMAR S, CREATSAS G, MASTORAKOS G: The effects of adipose tissue and adipocytokines in human pregnancy. Ann N Y Acad Sci 1205: 76-81, 2010.

VEJRAŽKOVÁ D, VAŇKOVÁ M, LUKÁŠOVÁ P, VČELÁK J, BRADNOVÁ O, PRAŽÁKOVÁ S, KVASNIČKOVÁ H, BENDLOVÁ B: Birth weight and genetic risk of type 2 diabetes in Czech population (in Czech). Vnitr Lek 56: 1303-1309, 2010.

VEJRAZKOVA D, LUKASOVA P, VANKOVA M, BRADNOVA O, VACINOVA G, VCELAK J, CIRMANOVA V, ANDELOVA K, KREJCI H, BENDLOVA B: Gestational diabetes - metabolic risks of adult women with respect to birth weight. Physiol Res 64: S135-S145, 2015.

VEJRAZKOVA D, LISCHKOVA O, VANKOVA M, STANICKA S, VRBIKOVA J, LUKASOVA P, VCELAK J, VACINOVA G, BENDLOVA B: Distinct response of fat and gastrointestinal tissue to glucose in gestational diabetes mellitus and polycystic ovary syndrome. Physiol Res 66: 283-292, $2017 \mathrm{a}$.

VEJRAŽKOVÁ D, VAŇKOVÁ M, LUKÁŠOVÁ P, VČELÁK J, BENDLOVÁ B: The response of fat and intestinal tissue to glucose load in women with a history of gestational diabetes: Is it affected by breastfeeding? (abstract) DMEV 20: 58-59, $2017 \mathrm{~b}$.

VICTORA CG, BAHL R, BARROS AJ, FRANÇA GV, HORTON S, KRASEVEC J, MURCH S, SANKAR MJ, WALKER N, ROLLINS NC; LANCET BREASTFEEDING SERIES GROUP: Breastfeeding in the 21st century: epidemiology, mechanisms, and lifelong effect. Lancet 387: 475-490, 2016.

VIDANALAGE CJ, SENARTH U, SILVA KD, LEKAMGE U, LIYANAGE IJ: Effects of initial body mass index on development of gestational diabetes in a rural Sri Lankan population: a case-control study. Diabetes Metab Syndr 10: S110-S113, 2016.

WEI JN, SUNG FC, LI CY, CHANG CH, LIN RS, LIN CC, CHIANG CC, CHUANG LM: Low birth weight and high birth weight infants are both at an increased risk to have type 2 diabetes among schoolchildren in Taiwan. Diabetes Care 26: 343-348, 2003.

WILLIAMS MA, EMANUEL I, KIMPO C, LEISENRING WM, HALE CB: A population-based cohort study of the relation between maternal birthweight and risk of gestational diabetes mellitus in four racial/ethnic groups. Paediatr Perinat Epidemiol 13: 452-465, 1999.

YANG X, BI P, KUANG S: Fighting obesity: when muscle meets fat. Adipocyte 3: 280-289, 2014.

YEUNG EH, HU FB, SOLOMON CG, CHEN L, LOUIS GM, SCHISTERMAN E, WILLETT WC, ZHANG C: Life-course weight characteristics and the risk of gestational diabetes. Diabetologia 53: 668-678, 2010.

ZHANG C, SOLOMON CG, MANSON JE, HU FB: A prospective study of pregravid physical activity and sedentary behaviors in relation to the risk for gestational diabetes mellitus. Arch Intern Med 166: 543-548, 2006.

ZHANG Y, YU H, GAO P, CHEN J, YU C, ZONG C, LU S, LI X, MA X, LIU Y, WANG X: The effect of growth hormone on lipid accumulation or maturation in adipocytes. Cell Physiol Biochem 39: 2135-2148, 2016.

ZHAO P, LIU E, QIAO Y, KATZMARZYK PT, CHAPUT JP, FOGELHOLM M, JOHNSON WD, KURIYAN R, KURPAD A, LAMBERT EV, MAHER C, MAIA JA, MATSUDO V, OLDS T, ONYWERA V, SARMIENTO OL, STANDAGE M, TREMBLAY MS, TUDOR-LOCKE C, HU G; ISCOLE RESEARCH GROUP: Maternal gestational diabetes and childhood obesity at age 9-11: results of a multinational study. Diabetologia 59: 2339-2348, 2016.

ZILBERLICHT A, FEFERKORN I, YOUNES G, DAMTI A, AUSLENDER R, RISKIN-MASHIAH S: The mutual effect of pregestational body mass index, maternal hyperglycemia and gestational weight gain on adverse pregnancy outcomes. Gynecol Endocrinol 32: 416-420, 2016. 